\title{
Assessing and Comparing the Fracture Strength of Typodont Versus Natural Teeth
}

\author{
Sathvika $\mathrm{K}^{1}$ and Anjaneyulu $\mathrm{K}^{2}$ \\ ${ }^{1}$ Saveetha Dental College, Saveetha Institute of Medical and Technical \\ Sciences, Saveetha University, Chennai - 600077, India \\ ${ }^{2}$ Reader, Department of Conservative Dentistry and Endodontics, Saveetha Dental College, Saveetha \\ Institute of Medical and Technical Sciences, Saveetha University, Chennai - 600077, India
}

\section{ABSTRACT}

Working on a live human tooth takes expertise that only comes with pre-clinical practice. The typodont is an educational model of the oral cavity used by dental students pre-clinically. But for efficient practice, a model with comparable physical properties is imperative. Fracture strength (FS) among a few others, is a very necessary component of understanding the structure and behaviour of a natural tooth. Thus, we have aimed to compare the FS to assess whether typodont teeth prove to be an apt representation of natural teeth to practise on pre-clinically. 10 samples were split into two groups Group 1 consisted of 5 natural premolars. Group 2 consisted of 5 typodont premolars. The FS of all the typodont teeth were higher than that of all the natural teeth. Thus, more force is required to cause a displacement within the material of the typodont teeth than in actual teeth, leading to a difference in work style. This hints that pre-clinical students and clinicians apply dissimilar pressures on their instruments while attempting to bring about the same results. The FS of typodont teeth and natural teeth are significantly dissimilar, thus enlightening the need for a different material to represent a human tooth pre-clinically.

\section{KEY WORDS: FRACTURE STRENGTH, TYPODONT TEETH, NATURAL TEETH, DISSIMILARITIES, PRE-CLINICAL.}

\section{INTRODUCTION}

Dentistry is a highly specialized and exacting science which requires the exercise of great skill. Since the development of such skill cannot be done without relentless systematic practice, it is logical to say that a trainee cannot, as a bud in training, be permitted to practice by trial and error on live patients and thus certain specialized training apparatuses that simulate the human

\section{ARTICLE INFORMATION}

*Corresponding Author: Kanjaneyulu.sdc@saveetha.com Received 11th June 2020 Accepted after revision 10th August 2020 Print ISSN: 0974-6455 Online ISSN: 2321-4007 CODEN: BBRCBA

Thomson Reuters ISI Web of Science Clarivate Analytics USA and Crossref Indexed Journal

\section{Clarivate
Analytics}

NAAS Journal Score 2020 (4.31) SJIF: 2020 (7.728)

A Society of Science and Nature Publication,

Bhopal India 2020. All rights reserved.

Online Contents Available at: http//www.bbrc.in/

Doi: http://dx.doi.org/10.21786/bbrc/13.7/71 jaw and tooth structures have been developed over time as pre-clinical aids (Garson, 1969). The most widely used training apparatus in use today is the typodont a typodont is an educational model of the oral cavity simulating teeth, the gingiva and the palate, used by dental and hygienist students pre-clinically. Typically, typodonts have replaceable teeth that can be screwedin, and are composed of materials that allow students to prepare cavities and fill them with restorative materials such as amalgam, composite or glass ionomer cement; bond orthodontic brackets or to prepare temporary teeth for crowns and bridges (Oliver and Volp, 1991; Titshall, McKnight and Hunt, 1996; Enochs et al., 2018).

The use of typodonts have established various advantages and disadvantages over the years. It is economical, easy to handle and standardised - allowing room for comfortable learning. The advent of new technology has also resulted 
in the use of entities like computer programmed mannequins (LeBlanc et al., 2004; Epps, White and Tofil, 2013; Hemmer, 2014) with sound indicators to alert the operator that the mannequin is in pain from an overprepared cavity to simulate a real patient. The computer-assisted simulator DentSim (Tavkar and Pawar, 2017), is a clinical counterfeit for pre-conservative work providing real-time tactile feedback using threedimensional graphics. It consists of a mannequin, a typodont with teeth and a set of rotary instruments (Welk et al., 2004, 2008). The attached infrared cameras and LEDs allow the user to visualise three-dimensional images of their work area from different angles and can also compare the student's preparation to an 'ideal preparation' already pre-fed into the computer (Zheng et al., 2014; Pavaloiu et al., 2016).

As remarkable as these replicas are, they still do pose with certain limitations. The apprehension of the patient to dental treatments is one of the most crucial walls that a dentist is met with in an actual practice (Kleinknecht, Klepac and Alexander, 1973; Jöhren et al., 2000; Erten, Akarslan and Bodrumlu, 2006). This psychological aspect can only be understood and dealt with while interacting with real patients in clinics and not on a typodont in a pre-clinical laboratory. Saliva is another such concern. The challenge of maintaining complete dry isolation (Costello, 2001) during a procedure from saliva is not encountered in a typodont and so pre-clinical work appears to be much easier. Similarly, the movement of a patient's tongue (Anthony, 1956), difference in the difficulty level of retraction of soft tissues, fogging of the mouth mirror (0'hara, 1958), varied mouth openings differing from patient to patient, the potential to close his/her mouth and the patient's tendency to move giving rise to a margin for gross error are all problems that occur only in real patients and not pre-clinically.

These are to be expected as they are beyond our current scientific outreach. But there are parameters such as the various physical properties of typodont teeth that can be controlled and optimised to bring about a better pre-clinical experience. To do so, we must assess each physical aspect and make a comparison between the two for natural and typodont teeth and propose a change in material if the physical properties are vastly different. One such important property is the fracture strength of teeth (Steagall, Ishikiriama and de Lima Navarro, 1980). Fracture strength or breaking strength is the ability of a material to resist failure and it is designated specifically according to the mode of applied loading such as tensile, compressive or bending stress; or it can be defined as the stress at which a specimen fails due to fracture (DeGarmo et al., 1997). It is commonly recorded for a given specimen through a tensile test which charts a stress-strain curve, where the final point represents the fracture strength.

The fracture strength of a typodont tooth and a natural tooth talks about how much stress it can take before it fractures, thus indirectly painting a picture about how much operator adaptation is needed while handling each type of tooth. Ideally, there should not be much of a difference between the two types of teeth and the need to adapt handling techniques between them should be minimal or none at all. If there is a large difference in the compressive stress at maximum force (fracture strength) between the two groups, it indicates that typodont teeth and natural teeth are physically dissimilar and that increases the need for adapting handling techniques while working between the two types of teeth, thus treating them as two different entities altogether - therefore destroying the purpose of a preclinical model for students to practice on before working on a real tooth.

We have numerous highly cited publications that are well designed clinical trials and lab studies (Govindaraju, Neelakantan and Gutmann, 2017; Azeem and Sureshbabu, 2018; Jenarthanan and Subbarao, 2018; Manohar and Sharma, 2018; Nandakumar and Nasim, 2018; Teja, Ramesh and Priya, 2018; Janani and Sandhya, 2019; Khandelwal and Palanivelu, 2019; Malli Sureshbabu et al., 2019; Poorni, Srinivasan and Nivedhitha, 2019; Rajakeerthi and Ms, 2019; Rajendran et al., 2019; Ramarao and Sathyanarayanan, 2019; Siddique and Nivedhitha, 2019; Siddique et al., 2019; Siddique, Nivedhitha and Jacob, 2019). This has provided the right platforms for us to pursue our present study. Hence, we have aimed to compare the fracture strength and to assess whether typodont teeth prove to be an apt representation of natural teeth to practise on pre-clinically because idealising pre-clinical models to represent real teeth as much as humanly possible is a great attempt to improve the efficiency of clinical performance.

\section{MATERIAL AND METHODS}

Study Design and Setting: A total of 10 samples were split into two groups and were tested for fracture strength using compressive stress in an Instron universal testing machine (UTM) (Annappa and Panditrao, 2012). The first group (Group 1) consisted of 5 natural mandibular first premolars that were free of caries, tooth wear, cracks and fractures and were freshly extracted for therapeutic reasons and were stored until required for use post disinfection. The second group (Group 2) consisted of 5 new unrestored Nissin typodont (PRO 2001-UL-HDHM-32) mandibular first premolars. The samples were embedded in auto-polymerizing acrylic resin blocks made from a putty polyvinyl siloxane $3 \times 3$ square mould and were mounted parallel to the long axis of the teeth. The graphs and values were obtained digitally and the compressive stress at maximum force was recorded in MPa units. The data obtained was collected for statistical analysis.

Data Collection and Statistical Analysis: Data was recorded in Microsoft Excel 2016 (Microsoft Office 10) and was later exported to the Statistical Package for the Social Sciences for Windows (Version 20.0, SPSS, Inc., Chicago, USA) and was then subjected to statistical analysis. An Independent-Samples T Test (Levene's Test 
for Equality of Variances \& T Test for Equality of Means) was used with the level of significance set at $p<0.05$.

Figure 1: Shows 5 samples from Group 1 (natural teeth) and Group 2 (typodont teeth) which were embedded in acrylic resin.

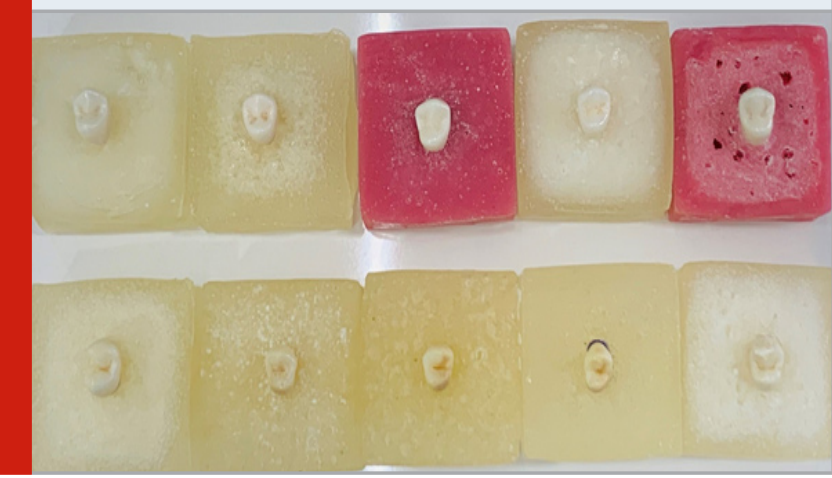

Figure 2: Showing a sample from Group 2 (a new unrestored Nissin typodont mandibular first premolar) mounted parallel to the long axis of the tooth and ready to be tested for its fracture strength in an Instron universal testing machine.

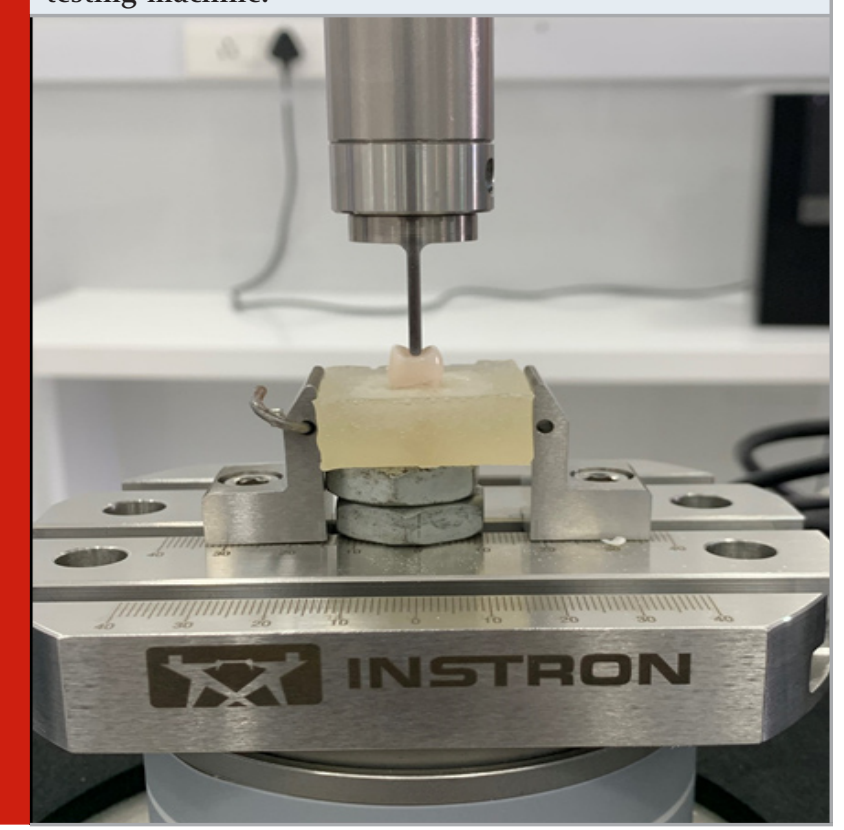

\section{RESULTS AND DISCUSSION}

The final dataset comprised of 10 samples of teeth which were evenly split into 2 groups - Group 1 and Group 2. Group 1 consisted of 5 natural mandibular first premolars that were free of caries, tooth wear, cracks and fractures and were freshly extracted for therapeutic reasons and were stored until required for use post disinfection. Group 2 consisted of 5 new unrestored Nissin typodont (PRO 2001-UL-HD-HM-32) mandibular first premolars. According to the results from Figure 4, there is a considerable difference in the fracture strengths of natural teeth when compared to that of typodont teeth. 5 out of 5 typodont samples have greater values of compressive stress at maximum force (MPa) than natural teeth.

Figure 3: Showing a sample from Group 2 (a new unrestored Nissin typodont mandibular first premolar) post fracture along with its broken half after being tested for fracture strength in an Instron universal testing machine. The fracture appears to be vertical and along the long axis of the tooth.

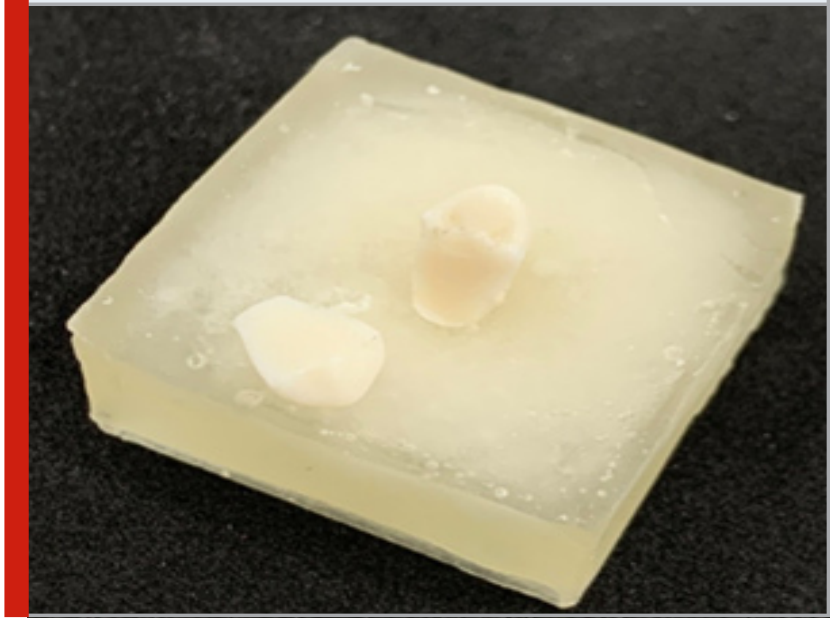

Figure 4: Bar chart representing the fracture strength for each sample where Group 1 (natural teeth) and Group 2 (typodont teeth) are in the ' $\mathrm{X}$ ' axis and the compressive stress at maximum force ( $\mathrm{MPa}$ ) is in the ' $\mathrm{Y}$ ' axis. Group 1 is represented by the colour light blue while Group 2 is represented by a darker blue, with the values of their individual compressive stresses at maximum force labelled above each bar column. It shows a clear difference in fracture strengths between the samples in Group 1 and 2, where the typodont teeth in Group 2 have a higher fracture strength when compared to the natural teeth in Group 1. (Independent-Samples T Test - Levene's Test for Equality of Variances \& $\mathrm{T}$ Test for Equality of Means, statistically significant ' $p$ ' value $-0.003, p<0.05$ )

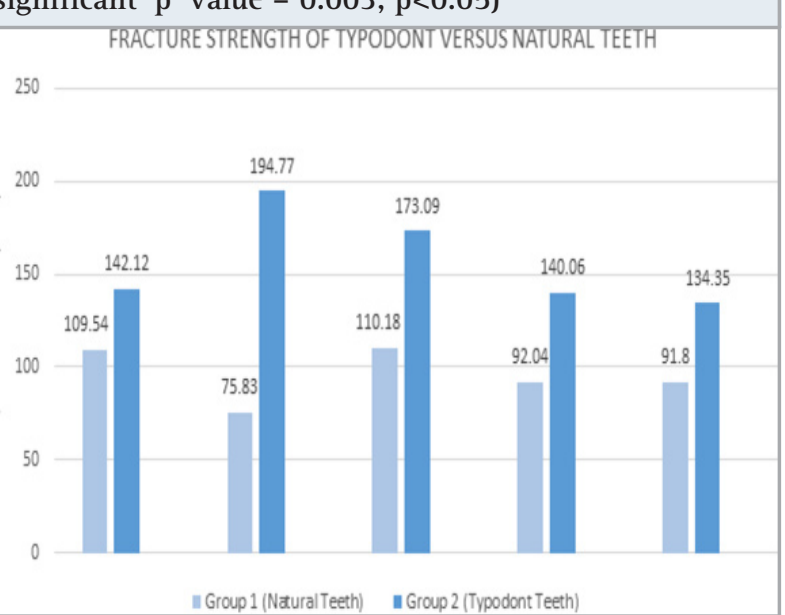


Figure 5: Bar chart representing the difference between the mean compressive stress at maximum force for Group 1 (natural teeth) and Group 2 (typodont teeth) where the ' $\mathrm{X}$ ' axis shows the two groups and the ' $\mathrm{Y}$ ' axis shows the compressive stress at maximum force in MPa units. The lighter blue represents the natural teeth in Group 1 and the darker blue represents the typodont teeth in Group 2. The mean compressive stress at maximum force for natural teeth (95.878 $\mathrm{MPa}$ ) is lower than that for typodont teeth (156.878 MPa) hinting that the fracture strength for typodont teeth is significantly higher. (IndependentSamples T Test - Levene's Test for Equality of Variances et T Test for Equality of Means, statistically significant 'p' value $-0.003, \mathrm{p}<0.05)$.

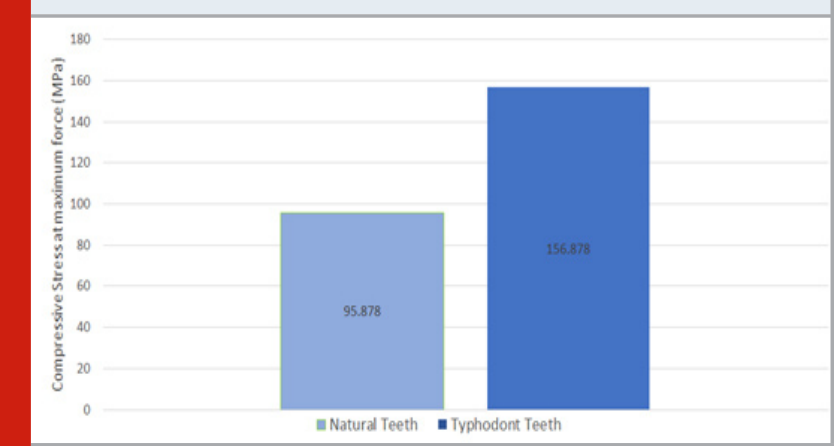

The values of compressive stress at maximum force for the natural tooth samples in Group 1 are 109.54 $\mathrm{MPa}, 75.83 \mathrm{MPa}, 110.18 \mathrm{MPa}$, 92.04 $\mathrm{MPa}$ and 91.8 $\mathrm{MPa}$ while the values for the same parameter in Group 2 are 142.12 MPa, 194.77 MPa, 173.09 MPa, 140.06 MPa and 134.35 MPa respectively. Interestingly, even the lowest value of $134.35 \mathrm{MPa}$ for typodont teeth is greater than the highest value of $110.18 \mathrm{MPa}$ for natural teeth. The means for compressive stress at maximum force (MPa) were calculated for both groups as inferred from Figure 5 , where the mean compressive stress at maximum force for natural teeth $(95.878 \mathrm{MPa})$ is lower than that for typodont teeth (156.878 $\mathrm{MPa}$ ) hinting that the fracture strength for typodont teeth is significantly higher. To check for statistical reliability, an Independent-Samples T Test - Levene's Test for Equality of Variances \& T Test for Equality of Means was carried out where we obtained the statistically significant 'p' value of 0.003 , where $p<0.05$. (Refer Table 1) This means that there is a significant difference in the fracture strength of the two materials, and that they have different physical properties.

As inferred from Table 2, the maximum force used among the samples of Group 1 for natural teeth was $1101.81 \mathrm{~N}$, which is comparable to a maximum force of $1192.30 \mathrm{~N}$ as used on intact natural premolar teeth (positive control group) in a study conducted by Göktürk et al. in 2018 (Göktürk et al., 2018). In contrast, the maximum force

Table 1. Tabulation showing the results of an Independent-Samples T Test - Levene's Test for Equality of Variances \& $\mathrm{T}$ Test for Equality of Means conducted between the compressive stress at maximum force (MPa) and the two groups of natural teeth (Group 1) and typodont teeth (Group 2) where we have obtained a statistically significant 'p' value of 0.003 where $p<0.05$ after rejecting our null hypothesis of equal variances assumed $(p=0.002)$. Hence, this means that there is a reliable difference between the compressive stress at maximum force for Group 1 and Group 2.

\begin{tabular}{|c|c|c|c|c|c|c|c|c|}
\hline \multirow{2}{*}{$\begin{array}{l}\text { Compressive Stress } \\
\text { at Maximum } \\
\text { Force (MPa) }\end{array}$} & \multirow{2}{*}{$\begin{array}{c}\text { Levene's Test for } \\
\text { Equality of } \\
\text { Variances }\end{array}$} & \multirow[b]{2}{*}{$\mathrm{F}$} & \multicolumn{6}{|c|}{ T-Test for Equality of Means } \\
\hline & & & Sig. & $t$ & df & $\begin{array}{c}\text { Sig. } \\
\text { (2 tailed) }\end{array}$ & $\begin{array}{c}\text { Mean } \\
\text { Difference }\end{array}$ & $\begin{array}{l}\text { Std. Error } \\
\text { Difference }\end{array}$ \\
\hline Equal Variances Assumed & & 3.878 & 0.084 & -4.591 & 8 & 0.002 & -61.000 & 13.288 \\
\hline $\begin{array}{l}\text { Equal Variances Not } \\
\text { Assumed }\end{array}$ & & & & -4.591 & 6.230 & 0.003 & -61.000 & 13.288 \\
\hline
\end{tabular}

used among the samples of Group 2 for typodont teeth was $1947.68 \mathrm{~N}$. This vast difference calls for the birth of new materials to replace the current acrylic used in typodont teeth to ensure a closer experience preclinically to real life practice.

Mandibular premolars were selected because they are easy to collect in the disease-free form (they are commonly extracted for orthodontic purposes) and have a single root. In addition, these teeth are highly susceptible to fracture and frequently require replacement prostheses. But testing other teeth like incisors, canines or molars may have yielded the possibility of different results. Since the study does present with such limitations, further research must be done to confirm the generalisability of our findings. 
Table 2. Tabulation showing the maximum force applied on the samples in both groups in newton units $(\mathrm{N})$, the compressive stress at maximum force in megapascal units $(\mathrm{MPa})$ and their means for compressive stress at maximum force - also in megapascal units (MPa).

\begin{tabular}{|l|l|c|c|}
\hline Group & $\begin{array}{l}\text { Maximum } \\
\text { Force [N] }\end{array}$ & $\begin{array}{l}\text { Compressive Stress at } \\
\text { Maximum Force [MPa] }\end{array}$ & $\begin{array}{l}\text { Mean } \\
\text { [MPa] }\end{array}$ \\
\hline \multirow{3}{*}{ Group 1 - Natural Teeth } & 1095.36 & 109.54 & 95.878 \\
\hline \multirow{5}{*}{ Group 2 - Typodont Teeth } & 758.25 & 75.83 & \\
\cline { 2 - 4 } & 1101.81 & 110.18 & \\
\cline { 2 - 4 } & 920.38 & 92.04 & \\
\cline { 2 - 4 } & 918.02 & 91.8 & \\
\hline & 1421.16 & 142.12 & \\
\hline & 1947.68 & 194.77 & \\
\hline & 1730.89 & 173.09 & 140.06 \\
\cline { 2 - 4 } & 1400.58 & 134.35 & \\
\cline { 2 - 4 } & 1343.47 & & \\
\hline
\end{tabular}

\section{CONCLUSION}

To ensure sound preparation for an actual clinical set-up, students must be given the closest possible resemblance to it pre-clinically. The fracture strengths of typodont teeth and natural teeth are significantly dissimilar, thus enlightening the need for a different material to represent a human tooth pre-clinically. Idealising pre-clinical models to represent real teeth as much as humanly possible is a great attempt to improve the efficiency of clinical performance. But since the study does present with limitations, further research needs to be done to confirm the validity of our findings.

\section{ACKNOWLEDGEMENTS}

The authors of this study would like to thank the editors and the authors of the journal - the source of scientific compilation for this research article.

Conflict of Interest: None declared.

\section{REFERENCES}

Annappa, C. M. and Panditrao, K. S. (2012) 'Application of value engineering for cost reduction-A case study of universal testing machine', International Journal of Advances in Engineering Sciences and Applied Mathematics. researchgate.net. Available at: https:// bit.ly/2En6mYe

Anthony, P. (1956) 'Tongue depressor', US Patent. Available at: https://patentimages.storage.googleapis. com/03/53/b 1/679e688b7fa03b/US2765785.pdf (Accessed: 30 June 2020).

Azeem, R. A. and Sureshbabu, N. M. (2018) 'Clinical performance of direct versus indirect composite restorations in posterior teeth: A systematic review', Journal of conservative dentistry: JCD, 21(1), pp. 2-9. Costello, W. J. (2001) 'Oral isolation device with evacuation chambers', US Patent. Available at: https:// patentimages.storage.googleapis.com/3b/3e/b7/
a34d308ce66a33/US6213772.pdf (Accessed: 30 June 2020).

DeGarmo, E. P. et al. (1997) Materials and process in manufacturing. Prentice Hall Upper Saddle River.

Enochs, T. et al. (2018) 'Cuspal flexure of compositerestored typodont teeth and correlation with polymerization shrinkage values', Dental materials: official publication of the Academy of Dental Materials. Elsevier, 34(1), pp. 152-160.

Epps, C., White, M. L. and Tofil, N. (2013) 'Mannequin Based Simulators', in Levine, A. I. et al. (eds) The Comprehensive Textbook of Healthcare Simulation. New York, NY: Springer New York, pp. 209-232.

Erten, H., Akarslan, Z. Z. and Bodrumlu, E. (2006) 'Dental fear and anxiety levels of patients attending a dental clinic', Quintessence international . search. ebscohost.com, 37(4), pp. 304-310.

Garson, C. H. (1969) 'Typodont', US Patent. Available at: https://patentimages.storage.googleapis.com/d4/ bb/19/5712427f6e9334/US3422536.pdf (Accessed: 30 June 2020).

Göktürk, H. et al. (2018) 'The effect of the different restorations on fracture resistance of root-filled premolars', BMC oral health, 18(1), p. 196.

Govindaraju, L., Neelakantan, P. and Gutmann, J. L. (2017) 'Effect of root canal irrigating solutions on the compressive strength of tricalcium silicate cements', Clinical oral investigations, 21(2), pp. 567-571.

Hemmer, N. (2014) 'Dental mannequin simulation device and system', US Patent. Available at: https:// patentimages.storage.googleapis.com/a 3/b $6 /$ c8/664f054029694f/US20140106326A1.pdf (Accessed: 30 June 2020).

Janani, K. and Sandhya, R. (2019) 'A survey on skills for cone beam computed tomography interpretation among endodontists for endodontic treatment procedure', Indian journal of dental research: official publication of Indian Society for Dental Research, 30(6), pp. 
834-838.

Jenarthanan, S. and Subbarao, C. (2018) 'Comparative evaluation of the efficacy of diclofenac sodium administered using different delivery routes in the management of endodontic pain: A randomized controlled clinical trial', Journal of conservative dentistry: JCD, 21(3), pp. 297-301.

Jöhren, P. et al. (2000) 'Fear reduction in patients with dental treatment phobia', The British journal of oral $\mathrm{Ct}$ maxillofacial surgery. Elsevier, 38(6), pp. 612-616.

Khandelwal, A. and Palanivelu, A. (2019) 'Correlation Between Dental Caries And Salivary Albumin In Adult Population In Chennai: An In Vivo Study', Brazilian Dental Science, 22(2), pp. 228-233.

Kleinknecht, R. A., Klepac, R. K. and Alexander, L. D. (1973) 'Origins and characteristics of fear of dentistry', Journal of the American Dental Association . Elsevier, 86(4), pp. 842-848.

LeBlanc, V. R. et al. (2004) 'A preliminary study in using virtual reality to train dental students', Journal of dental education. Wiley Online Library, 68(3), pp. 378-383. Malli Sureshbabu, N. et al. (2019) 'Concentrated Growth Factors as an Ingenious Biomaterial in Regeneration of Bony Defects after Periapical Surgery: A Report of Two Cases', Case reports in dentistry, 2019, p. 7046203.

Manohar, M. P. and Sharma, S. (2018) 'A survey of the knowledge, attitude, and awareness about the principal choice of intracanal medicaments among the general dental practitioners and nonendodontic specialists', Indian journal of dental research: official publication of Indian Society for Dental Research, 29(6), pp. 716-720.

Nandakumar, M. and Nasim, I. (2018) 'Comparative evaluation of grape seed and cranberry extracts in preventing enamel erosion: An optical emission spectrometric analysis', Journal of conservative dentistry: JCD, 21(5), pp. 516-520.

O'hara, A. W. (1958) 'Anti-fogging device for dental mirrors', US Patent. Available at: https://patentimages. storage.googleapis.com/3b/62/e5/1e6b8aab00eae7/ US2834109.pdf (Accessed: 30 June 2020).

Oliver, R. G. and Volp, C. R. (1991) 'A “bonding” typodont', British journal of orthodontics, 18(4), pp. 323-327.

Pavaloiu, I. B. et al. (2016) 'Inexpensive dentistry training using virtual reality tools', in INTED2016, The 10th annual International Technology, Education and Development Conference. vir-pro.ro. Available at: http://www.vir-pro.ro/etapa\%203/Articol\%201.pdf. Poorni, S., Srinivasan, M. R. and Nivedhitha, M. S. (2019) 'Probiotic strains in caries prevention: A systematic review', Journal of conservative dentistry: JCD, 22(2), pp. 123-128.

Rajakeerthi, R. and Ms, N. (2019) 'Natural Product as the
Storage medium for an avulsed tooth - A Systematic Review', Cumhuriyet Dental Journal, 22(2), pp. 249256.

Rajendran, R. et al. (2019) 'Comparative Evaluation of Remineralizing Potential of a Paste Containing Bioactive Glass and a Topical Cream Containing Casein Phosphopeptide-Amorphous Calcium Phosphate: An in Vitro Study', Pesquisa brasileira em odontopediatria e clinica integrada, 19(1), pp. 1-10.

Ramarao, S. and Sathyanarayanan, U. (2019) 'CRA Grid - A preliminary development and calibration of a paper-based objectivization of caries risk assessment in undergraduate dental education', Journal of conservative dentistry: JCD, 22(2), pp. 185-190.

Siddique, R. et al. (2019) 'Qualitative and quantitative analysis of precipitate formation following interaction of chlorhexidine with sodium hypochlorite, neem, and tulsi', Journal of conservative dentistry: JCD, 22(1), pp. 40-47.

Siddique, R. and Nivedhitha, M. S. (2019) 'Effectiveness of rotary and reciprocating systems on microbial reduction: A systematic review', Journal of conservative dentistry: JCD, 22(2), pp. 114-122.

Siddique, R., Nivedhitha, M. S. and Jacob, B. (2019) 'Quantitative analysis for detection of toxic elements in various irrigants, their combination (precipitate), and para-chloroaniline: An inductively coupled plasma mass spectrometry study', Journal of conservative dentistry: JCD, 22(4), pp. 344-350.

Steagall, L., Ishikiriama, A. and de Lima Navarro, M. F. (1980) 'Fracture strength of human teeth with cavity preparations', Journal of prosthetics and orthotics: JP0. thejpd.org. Available at: https://www.thejpd.org/ article/0022-3913(80)90213-9/pdf.

Tavkar, A. and Pawar, A. (2017) 'Simulation in dentistry', EC Dental Science. academia.edu, 12, pp. 115-121.

Teja, K. V., Ramesh, S. and Priya, V. (2018) 'Regulation of matrix metalloproteinase-3 gene expression in inflammation: A molecular study', Journal of conservative dentistry: JCD, 21(6), pp. 592-596.

Titshall, M. J., McKnight, M. M. and Hunt, N. P. (1996) 'Direct bonding to typodont teeth', British journal of orthodontics. Taylor \& Francis, 23(1), pp. 65-67.

Welk, A. et al. (2004) 'DentSim - a future teaching option for dentists', International journal of computerized dentistry. europepmc.org, 7(2), pp. 123-130.

Welk, A. et al. (2008) 'Computer-assisted learning and simulation lab with 40 DentSim units', International journal of computerized dentistry. ncbi.nlm.nih.gov, 11(1), pp. 17-40.

Zheng, J. W. et al. (2014) 'An introduction of DentSim in pre-clinical dental training and practice', Shanghai kou qiang yi xue= Shanghai journal of stomatology. europepmc.org, 23(6), pp. 749-754. 